\title{
Compression Ratio Effect on Methane HCCI Combustion
}

\author{
Salvador M. Aceves \\ J. Ray Smith \\ Charles Westbrook \\ William Pitz \\ This paper was prepared for submittal to the \\ ASME Combustion Engine 1998 Fall Conference \\ Clymer, NY \\ September 26-30, 1998
}

September 29, 1998

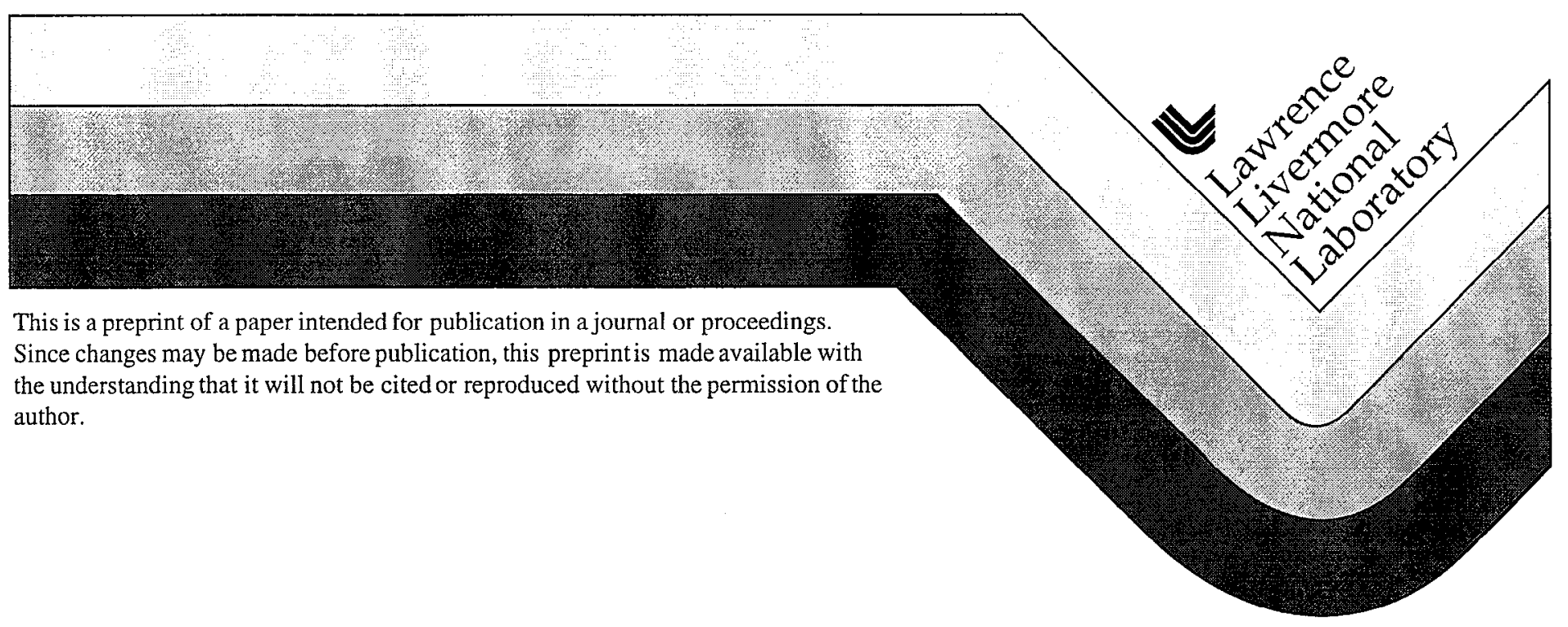




\section{DISCLAIMER}

This document was prepared as an account of work sponsored by an agency of the United States Government. Neither the United States Government nor the University of California nor any of their employees, makes any warranty, express or implied, or assumes any legal liability or responsibility for the accuracy, completeness, or usefulness of any information, apparatus, product, or process

disclosed, or represents that its use would not infringe privately owned rights. Reference herein to any specific commercial product, process, or service by trade name, trademark, manufacturer, or otherwise, does not necessarily constitute or imply its endorsement, recommendation, or favoring by the United States Government or the University of California. The views and opinions of authors expressed herein do not necessarily state or reflect those of the United States Government or the University of California, and shall not be used for advertising or product endorsement purposes. 


\title{
COMPRESSION RATIO EFFECT ON METHANE HCCI COMBUSTION
}

\author{
Salvador M. Aceves, J. Ray Smith, Charles Westbrook and William Pitz
}

\author{
Lawrence Livermore National Laboratory, \\ 7000 East Avenue, L-641 \\ Livermore, CA 94550, USA \\ saceves@llni.gov \\ jrsmith@llnl.gov \\ westbrook1@IInl.gov \\ pitz1@llnl.gov
}

\section{ABSTRACT}

We have used the HCT (Hydrodynamics, Chemistry and Transport) chemical kinetics code to simulate $\mathrm{HCCI}$ (homogeneous charge compression ignition) combustion of methane-air mixtures. $\mathrm{HCT}$ is applied to explore the ignition timing, bum duration, $\mathrm{NO}_{\mathrm{x}}$ production, gross indicated efficiency and gross IMEP of a supercharged engine ( $3 \mathrm{~atm}$. Intake pressure) with 14:1, 16:1 and 18:1 compression ratios at $1200 \mathrm{rpm}$. HCT has been modified to incorporate the effect of heat transfer and to calculate the temperature that results from mixing the recycled exhaust with the fresh mixture. This study uses a single control volume reaction zone that varies as a function of crank angle. The ignition process is controlled by adjusting the intake equivalence ratio and the residual gas trapping (RGT). RGT is internal exhaust gas recirculation which recycles both thermal energy and combustion product species. Adjustment of equivalence ratio and RGT is accomplished by varying the timing of the exhaust valve closure in either 2-stroke or 4-stroke engines. Inlet manifold temperature is held constant at $300 \mathrm{~K}$. Results show that, for each compression ratio, there is a range of operational conditions that show promise of achieving the control necessary to vary power output while keeping indicated efficiency above $50 \%$ and $\mathrm{NO}_{\mathrm{x}}$ levels below $100 \mathrm{ppm}$. HCT results are also compared with a set of recent experimental data for natural gas.

\section{NOMENCLATURE}

BDC - bottom dead center

$\mathrm{CAD}$ - crank angle degrees

DI - direct injected

EGR - exhaust gas recirculation

RGT - residual gas trapping (in-cylinder EGR)
RON - research octane number

TDC - top dead center

\section{INTRODUCTION}

The concept of homogeneous charge compression ignition ( $\mathrm{HCCI}$ ) has been described before by a number of researchers. Onishi, et al. (1979) experimentally studied homogeneous charge compression ignition in a two-stroke engine and achieved low cyclic variation at idle and up to $40 \%$ load. Najt and Foster (1983) used a simplified kinetics scheme to correlate heat release in a Waukesha Cooperative Fuels Research (CFR) engine with modest compression ratios and high EGR. Thring (1989) used a Labeco Cooperative Lubricant Research (CLR) engine with a wedge shaped combustion chamber at 8:1 compression ratio with external mixture preparation and heating of a gasoline mixture above $640 \mathrm{~K}$ and EGR rates of 13 to $33 \%$ to map out permissible operating parameters. Thring also coined the most descriptive name of this combustion process, $\mathrm{HCCl}$, which these authors will use in this work. Ryan and Callahan (1996) used a variable compression ratio engine to map operational space for $\mathrm{HCCl}$ using 47 cetane diesel fuel. They found that compression ratio, EGR rate and equivalence ratio were adequate for control. Nakagome et al. (1997) used early injection of diesel fuel in a DI Diesel to achieve $\mathrm{HCCl}$ resulting in very low $\mathrm{NO}_{\mathbf{x}}(20 \mathrm{ppm})$.

Recent research and development in $\mathrm{HCCl}$ combustion includes the successful testing of an experimental motorcycle with a 2-stroke $\mathrm{HCCl}$ (or activated radical combustion, ARC, as called by the authors) engine by Honda. The motorcycle participated in the Granada-Dakar rally, and placed fifth overall (Automotive 
Engineering, 1997). Other publications by Honda researchers (Asai et al., 1995; Ishibashi and Asai, 1996; Ishibashi and Asai, 1998) have described many technical details of the engine and motorcycle. The engine uses spark ignition for starting and for very low and very high load conditions, and an exhaust valve to regulate the amount of residual gas trapped (RGT) to achieve combustion control under $\mathrm{HCCl}$ combustion. Experimental testing has determined that the $\mathrm{HCCl}$ engine provides reduced $\mathrm{CO}$ and $\mathrm{HC}$ cmissions, a $27 \%$ improvement in fuel economy, and a marked improvement in driveability with respect to conventional 2-stroke engines.

Another recent publication has determined the fuel sensitivity of HCCI (Iida, 1997). Dimethyl ether, methanol, ethanol, methanc, and propane were tested in a 2-stroke, low compression ratio engine. Rescarch for 4-stroke engines (Gray and Ryan, 1997; Christensen et al, 1998) have once more demonstrated the benefits of HCCI of having a very high efficiency and low $\mathrm{NO}_{\mathbf{x}}$. A high IMEP has also been achieved by supercharging to 3 bar absolute pressure. These papers also indicate some drawbacks for $\mathrm{HCCl}$ combustion, including very sudden (and often early) heat release, and high hydrocarbons and $\mathrm{CO}$ emissions. Hydrocarbons and $\mathrm{CO}$ have been attributed by these researchers to wall wetting, wall quench and/or crevices. Gray and Ryan (1997) also measured a significant amount of particulate matter emissions. These may be due to the long-chain hydrocarbons and/or wall wetting in the experiments.

A very important issue regarding $\mathrm{HCCl}$ combustion is control of heat release. The HCCI process gives up two important control aspects: 1) the timing of the start of ignition is not directly controlled by any external event such as the beginning of injection in the standard Diesel or the sparking of the spark plug in the Otto cycle engine, and 2) the heat release rate is not controlled by either the rate and duration of the fuel injection process as in the standard Diesel or by the finite turbulent flame propagation time in the Otto cycle engine. A possibility for achieving engine control is by regulating the amount of RGT in the cylinder as a function of the engine load, and by using spark ignition for conditions where $\mathrm{HCCl}$ combustion is not satisfactory. This is the procedure used by Honda in the 2-stroke motorcycle engine. Use of RGT can also be applied to 4-stroke engines for combustion control, although its implementation is more complex than for 2-stroke engines. Previous work by the authors (Smith et al., 1997) describes an active control strategy that can be applied to an engine that includes an in-cylinder pressure sensor. With this strategy, variable valve timing and equivalence ratio are used for controlling combustion. If the pressure information indicates that the previous combustion cycle occurred later than the ideal timing for maximum efficiency, the mixture equivalence ratio can be increased for the next cycle. Note that this only requires a fast response time, low pressure injection system similar to that used in loday's port injection gasoline engines. Or altematively, if electromagnetic intake and exhaust valves are used (Theobald and Henry, 1994), the exhaust valve can be opened late to increase incylinder EGR and initial temperature for the next cycle. Calculations show that variations in the exhaust valve timing can be used to change the charge temperature at BDC by several hundred Kelvins due to changes in the amount of trapped hot residual gases kept in the cylinder for the next cycle. An electromagnetic intake valve timing can also be used to vary the initial charge density without suffering throttling losses. Through detailed kinetic modeling, the conditions required to control the initiation of autoignition can be predicted. The calculation of the required changes to keep the combustion starting at the proper time could be used to generate a look up table for the engine controller thus avoiding any real time detailed calculations.

Another alternative for controlling combustion consists of preheating the intake air to a temperature high enough for $\mathrm{HCCI}$ combustion to occur. This operating mode has often been tested in previous experiments (Christensen et al., 1998). This strategy could potentially be implemented in an engine by adding a heat exchanger to preheat the intake gases with the exhaust gases. This is in many respects a recycling of the exhaust thermal energy, similar to RGT. However, this methodology may be difficult to implement in vehicular applications, due to the long response time of the heat exchanger, and the extra volume and pressure drop that results from heat exchanger operation.

As an alternative to the above ignition control strategies, it is also possible to raise the temperature and the density of the charge by firing a spark plug and start a flame propagating that will further compress the unburned mixture. This would be a very slow flame in the lean, low turbulence mixture and would not have time to propagate across the chamber before conditions in the unburned gases reached the autoignition point. This type of operation, if required, would in effect be an Otto cycle engine process with "soft knock" due to the very lean operation. Yet another ignition alternative is to direct inject either near TDC or at the intake valve a small amount of high cetane fuel to promote earlier autoignition. Injection near TDC would be the equivalent to pilot injection diesel operation which has been used in some diesel dual fuel operation on natural gas (Jensen, 1994). Neither of these alternatives are as desirable due to cost and complexity, but they do exist as backups if the preferred control is too sensitive to be a robust control strategy. This paper explores only the use of extemally prepared equivalence ratio and RGT as controls.

Our concept of $\mathrm{HCCl}$ is to use compression ignition of a homogeneous charge mixture prepared in the manifold of a very high octane (and low cetane) fuel at very lean conditions. This is contrasted to earlier work (Thring, 1989) where a 87 octane fuel was used at $8: 1$ compression ratio or the early direct injection studies (Nakagome, et al., 1997) at 16.5:1 compression ratio using a 62 cetane fuel. In our current study we have chosen methane as the fuel with its $120 \mathrm{RON}$. Ignition is by autoignition thus relatively high compression ratios will be needed. Because the mixture is homogeneous and lean, no particulates will be formed. Thermal efficiency in an $\mathrm{HCCl}$ engine is likely to closely approach that of the standard diesel as was demonstrated by Thring (1989). 


\section{COMPUTATIONAL MODEL}

All of the modeling computations in this study were carried out using the HCT model (Hydrodynamics, Chemistry and Transport; Lund, 1978). This model has been used in a large number of investigations over the years, and in particular was used in past studies of engine knock and autoignition (Westbrook, et al., 1991; Pitz et al., 1991, Westbrook et al., 1988). The HCT code permits the use of a variety of boundary and initial conditions for reactive systems, depending on the needs of the particular system being examined. In the present case, the relevant conditions are those which describe the bulk gases in the combustion chamber.

Autoignition of a homogeneous charge is virtually identical to the knock process that can occur in the Otto cycle engine. From detailed kinetic modeling of motored engines using a homogeneous charge of a variety of fuels, it is known that the controlling parameters in the initiation of this process are the fuel components (mixtures behave differently than neat fuels), and the temperarure and density history that the fuel air mixture experiences. Motored engine experiments at General Motors Research Laboratories (Curran et al., 1995) agree well with HCT simulation of this process. Thus if the precise conditions at the start of compression are known (species, temperature and density), the beginning of combustion can be accurately predicted.

During an engine cycle, a number of processes occur which influence the time variation of the temperature and pressure of the bulk reactive gases in the combustion chamber. Piston motion first compresses and heats the bulk gases and then expands and cools them. During this time chemical reactions release heat and change the overall composition of the gases. Fresh unreacted fuel and air are added to hot residual gases left over from the previous cycle. Residual gases from the previous engine cycles which consist largely of water vapor, $\mathrm{CO}_{2}$ and molecular nitrogen and oxygen are assumed fully mixed with the fresh charge. In addition, heat losses to the engine chamber walls, blowby, fuel trapping in crevice volumes, and other processes occur. Of these, in the current simulations, only heat transfer losses are taken into account.

The computational model treats the combustion chamber as a homogeneous reactor with a variable volume. The mixed temperature of the residual gases and the fresh charge is estimated by a published procedure (Heywood, 1988). Equivalence ratio is defined as that of the incoming mixture in the manifold - not the mixture in the cylinder which can be leaner due to residual oxygen. The volume is changed with time using a slider-crank formula as described by Heywood (1988) and used in previous modeling studies (Westbrook et al.,1991; Green et al., 1987). The heat transfer submodel that we employed in the HCT code simulations uses Woschni's correlation (Woschni, 1967).

The present analysis considers a single-zone, lumped model that ignores spatial variations in the combustion chamber, treating heat loss as a distributed heat transfer rate, proportional to the temperature difference between the average gas temperature and a time-averaged wall temperature. The authors recognize that this is a great oversimplification of the actual condition within the combustion chamber. In particular, the boundary layer which contains significant mass must be at a lower temperature than the bulk gas near TDC. Due to the extreme temperature history sensitivity of the autoignition and heat release processes, our estimates of burn duration will be shorter than in experiments. That is, the boundary layer will always burn last and extend the heat release rate compared to this simulation. Peak cylinder pressure and rate of pressure rise are overestimated with the single-zone model, and the model cannot accurately predict $\mathrm{CO}$ and hydrocarbon emissions, which have been explained as depending on crevices, or wall wetting and quenching. On the other hand, predictions of start of combustion and NO, which depend on the peak temperature of the gases inside the cylinder, are expected to be accurate. These expectations are verified in a later section of this paper, where the model results are compared with recent experimental results for natural gas. The ideal computational tool for a detailed $\mathrm{HCCl}$ analysis would be a combination of $\mathrm{HCT}$ and a fluid mechanics code, such as KIVA (Amsden, 1993), where the cylinder is divided into a great number of zones, each one with a different temperature history. This is, however, well beyond our current computational capabilities. KIVA has been used in the past to predict $\mathrm{HCCl}$ combustion, but simplified correlations for heat release have been used, instead of detailed chemical kinetics (Kong et al., 1992; Hashizume et al., 1998).

Each simulation is started at BDC. The intake gases, initially at $300 \mathrm{~K}$, are compressed in a supercharger to 3 atmospheres absolute pressure and circulated through an intercooler with a $70 \%$ effectiveness before mixing with the trapped residuals in the cylinder. The cylinder wall, piston and head are all assumed to be at a uniform $500 \mathrm{~K}$. The chemical reactions are computed explicitly in the kinetics model. Thermodymamic table values of $c_{p}$ and $c_{v}$ are explicitly calculated to account for enthalpy and pressure changes. The simulation is stopped at BDC and the indicated efficiency is computed. The NO values reported are those at BDC. The chemical kinetic reaction mechanisms used by the model for methane ignition and NO production have been extremely well established and are widely used. The chemical kinetic mechanism for methane was taken from Curran et al. (1995). The mechanism for nitrogen kinetics is from the Gas Research Institute mechanism version 1.2 (Frenklach et al., 1995). Other fuels can be analyzed with HCT, provided that the appropriatc chemistry reaction set is available. However, the computational resources necessary for running a problem increase rapidly as the complexity of the molecules increases.

\section{ENGINE DESCRIPTION}

The engine is assumed to have a bore and stroke of $100 \mathrm{~mm}$ and a connecting rod length of $160 \mathrm{~mm}$. Three compression ratios are analyzed: $14: 1 ; 16: 1$ and $18: 1$, and the displacement per cylinder is 0.785 liter. The engine is assumed to have variable valve timing for the exhaust so as to allow quick changes in the RGT. This 
arrangement allows near adiabatic EGR which means that the charge temperature rises with RGT fraction. The engine is assumed to be unthrottled at all operation points with a volumetric efficiency of $100 \%$. The engine speed is $1200 \mathrm{rpm}$ and the absolute intake pressure is 3 atmospheres.

\section{RESULTS}

By making over one hundred simulation runs we have mapped the regions of acceptable operation in the HCCI mode. Most of the results presented in this section are for a 16:1 compression ratio, which was chosen as the base-case. Figure 1 shows the results in equivalence ratio versus RGT fraction parameter space. The lower left of the plot shows the region where only partial burn or no bum takes place. The boundary between partial burn and complete burn was found to be extremely sharp. The upper right region represents the region where the acceptable operation both in terms of ignition timing and maximum cylinder pressure can be achieved.

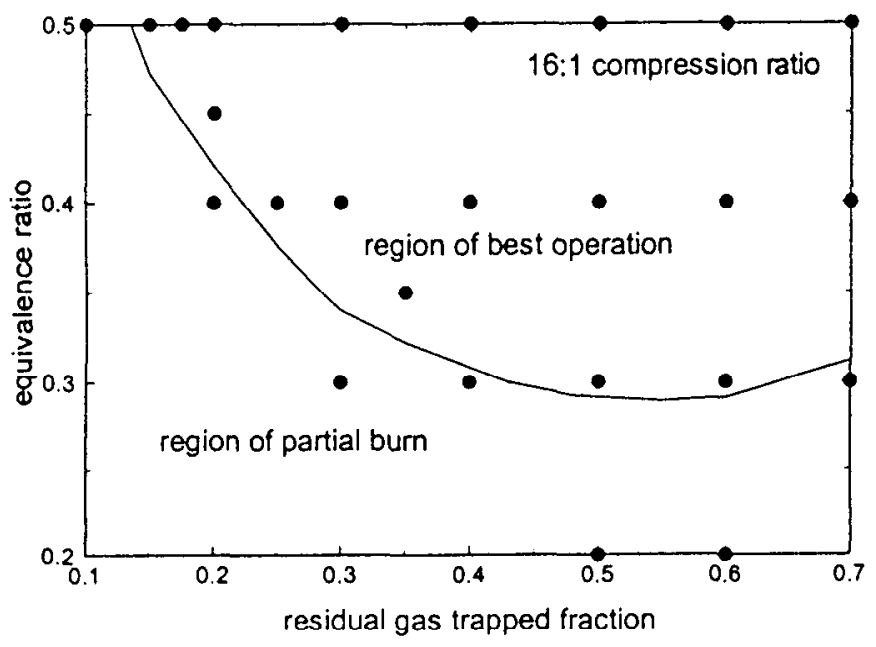

Figure 1. Map of the regions of acceptable operation in the $\mathrm{HCCl}$ mode for an engine with a 16:1 compression ratio at $1200 \mathrm{rpm}$ and 3 atmospheres of absolute pressure at the intake, running on methane. Points indicate simulations done with HCT code.

The bum duration is shown in Figure 2. Bum duration is defined as the crank angle between the points of $10 \%$ and $90 \%$ of heat release. All burn durations are noticeably short. We have included burn durations down to 2 CAD in the acceptable region which may be overly optimistic. Recall, however, that the single zone model used in the current simulations will, almost certainly, under predict the actual burn duration. Reasonable bum durations exist mainly for low equivalence ratios.
The gross indicated efficiency is shown in Figure 3. The efficiency is higher than $54 \%$ throughout the region of best operation. This area of high efficiency is at low power levels and potentially has much higher efficiency than spark-ignited engines due primarily to the lack of throttling losses and perhaps even higher than diesels due to shorter heat release rates. The efficiency increases as the equivalence ratio and RGT are decreased. For high equivalence ratios and RGT, combustion occurs before TDC, resulting in significant negative work on the piston. Reducing the equivalence ratio and RGT delays combustion and reduces the negative work, increasing the efficiency. Efficiencies in Figure 3 are optimistic values, since no losses due to blowby or partial combustion are considered in the analysis.

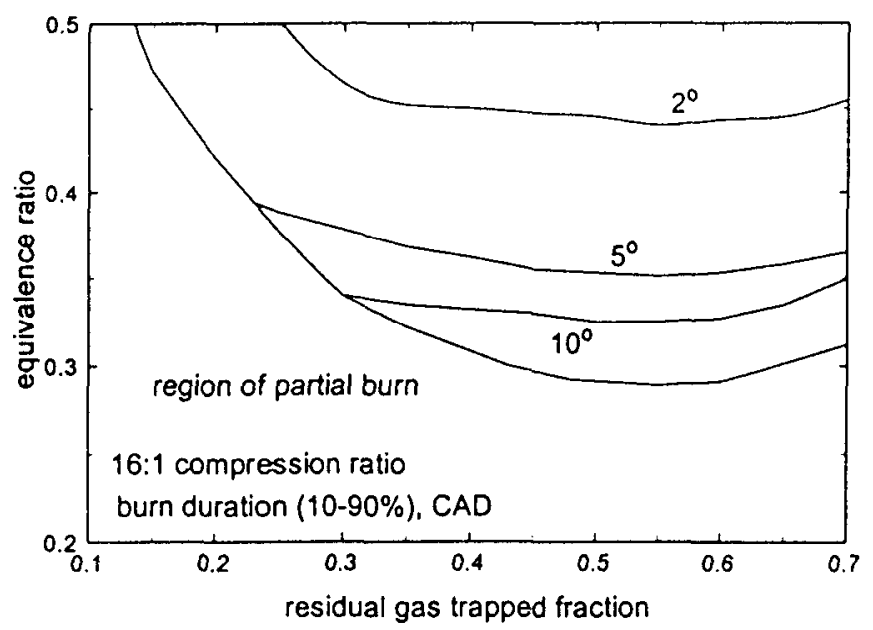

Figure 2. Burn duration (defined as the crank angle between the points of $10 \%$ and $90 \%$ of heat release) in crank angle degrees in the region of best $\mathrm{HCCl}$ operation for $1200 \mathrm{rpm}$.

Figure 4 shows the maximum pressure inside the cylinder. Maximum cylinder pressure may be limited due to the mechanical strength of the engine. A recent publication (Christensen et al., 1998) set the maximum cylinder pressure at 250 bar. The maximum pressure is high over a large portion of the operational space, but it does not reach $250 \mathrm{bar}$, and it is therefore considered acceptabic.

Figure 5 shows engine gross IMEP (indicated mean effective pressure) in bar. The maximum IMEP is high, being of the same order as the IMEP for spark-ignited engines (Heywood, 1988) Obtaining a high power out of an $\mathrm{HCCl}$ engine is a concern, due to the need to operate at a low equivalence ratio and a high RGT. Figure 5 shows that supercharging may provide the high power when this is required.

The NO emissions were found to be more than $98 \%$ of the total $\mathrm{NO}_{\mathrm{x}}$ emission. They are plotted in Figure 6. As expected when the equivalence ratio rises above $0.4, \mathrm{NO}$ emissions rise quickly, and this 
is another reason to keep the equivalence ratio under 0.5 (in addition to a high maximum cylinder pressure and early combustion).

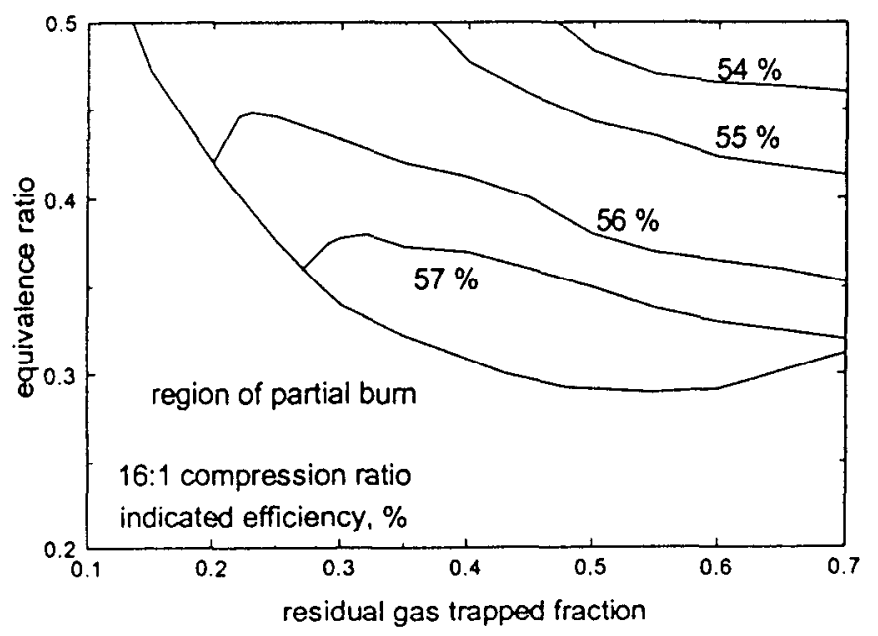

Figure 3. Gross indicated efficiency in the best region of operation at $1200 \mathrm{rpm}$.

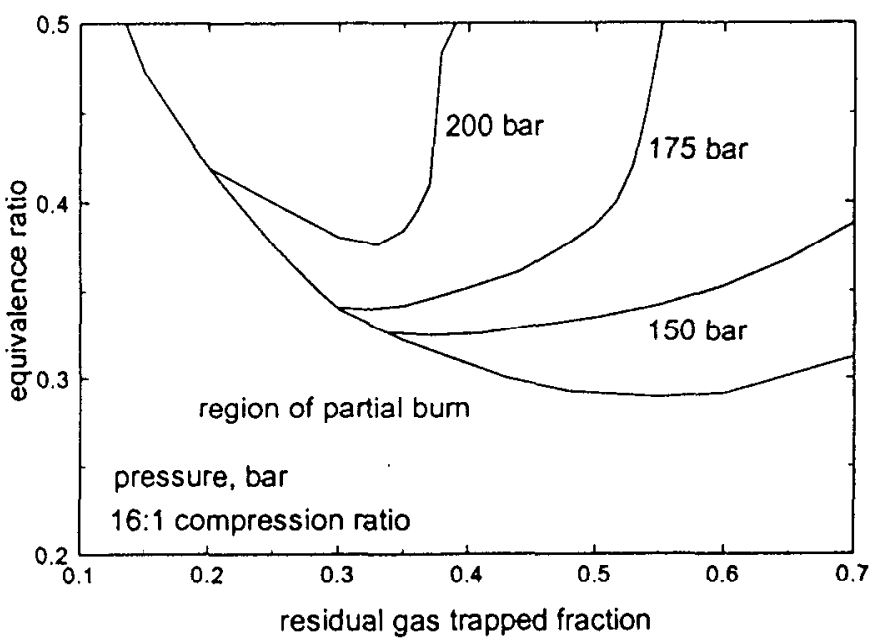

Figure 4. Contours of maximum cylinder pressure for methane $\mathrm{HCCl}$ combustion at 16:1 CR, $1200 \mathrm{rpm}$ and 3 atmospheres of absolute intake pressure.

As the compression ratio is reduced, the peak temperature in the cylinder is lower, reducing the likelihood of fuel $\mathrm{HCCl}$ combustion. This is illustrated in Figure 7, where the area of best $\mathrm{HCCl}$ operation is mapped as a function of equivalence ratio and RGT for an engine with a $14: 1$ compression ratio. Comparing Figure 7 with Figure 1 (for $16: 1 \mathrm{CR}$ ) shows that the area of best operation is reduced, due to the lower temperatures and pressures reached at the $14: 1 \mathrm{CR}$. Advantages of the lower CR operation include lower peak pressure, longer combustion, and an engine efficiency and IMEP that are almost as high as for the $16: 1 \mathrm{CR}$ case.

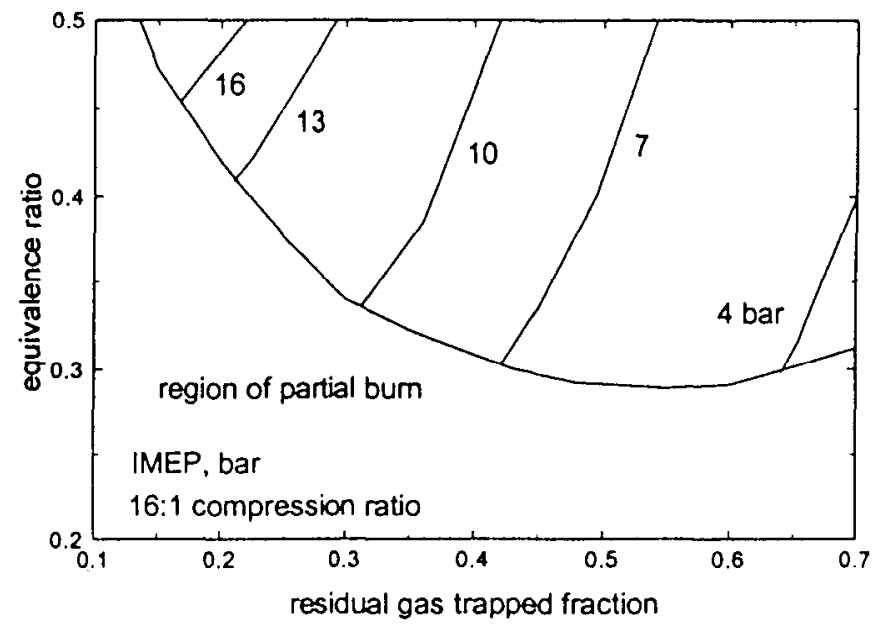

Figure 5. Contours of engine gross IMEP (indicated mean effective pressure) in bar for methane $\mathrm{HCCl}$ combustion at 16:1 CR, $1200 \mathrm{rpm}$ and 3 atmospheres of absolute intake pressure.

Figure 8 shows the mapping of the area of best operation for the $\mathrm{HCCI}$ engine with an 18:1 compression ratio. Comparing this figure with Figure 1 (for 16:1 CR), shows that the region of best operation extends down to lower equivalence ratios, due to the higher temperature and pressure achieved at the higher compression ratio. The figure also shows a zone in which the maximum cylinder pressure is greater than 250 bar. As previously discussed, this area may be excluded from the allowable operating area due to engine design constraints. A region is also shown in the upper right comer where combustion occurs too early (before $10^{\circ}$ BTDC). This area may also be excluded due to the great amount of negative work done on the cylinder and also due to the potential for high stresses in the bearings and crankshaft.

Figure 8 shows that the region of excessive peak pressure appears in the operating range that produces the maximum IMEP (high equivalence ratio and low RGT). It is therefore possible that the maximum IMEP for an engine with a maximum pressure constraint may be obtained at some intermediate, optimum, compression ratio. Figure 9 illustrates this. Figure 9 shows gross IMEP as a function of maximum cylinder pressure, for the three compression ratios being analyzed. The lines are obtained assuming operating conditions in the proximity of (slightly above) the partial burn line (for smooth combustion), and IMEP is controlled by moving along this line. Lowest power is obtained at the right end of the partial burn line, and maximum power is obtained at the opposite 
(upper left) end of the partial burn line (see Figures 1, 7 and 8). Figure 9 shows that the 250 bar restriction in the maximum pressure limits the power output from the 18:1 CR engine, so that the maximum IMEP is obtained from the 16:1 CR engine. Reducing the maximum cylinder pressure results in a reduced optimum compression ratio. An engine designed for a 200 bar maximum cylinder pressure would have $14: 1$ as the compression ratio for maximum IMEP. This procedure can be applied to determine the compression ratio for which a maximum IMEP is obtained for a given fuel, engine, and operating conditions. An evaluation of this optimum compression ratio should help in characterizing any fuel for $\mathrm{HCCl}$ engine operation.

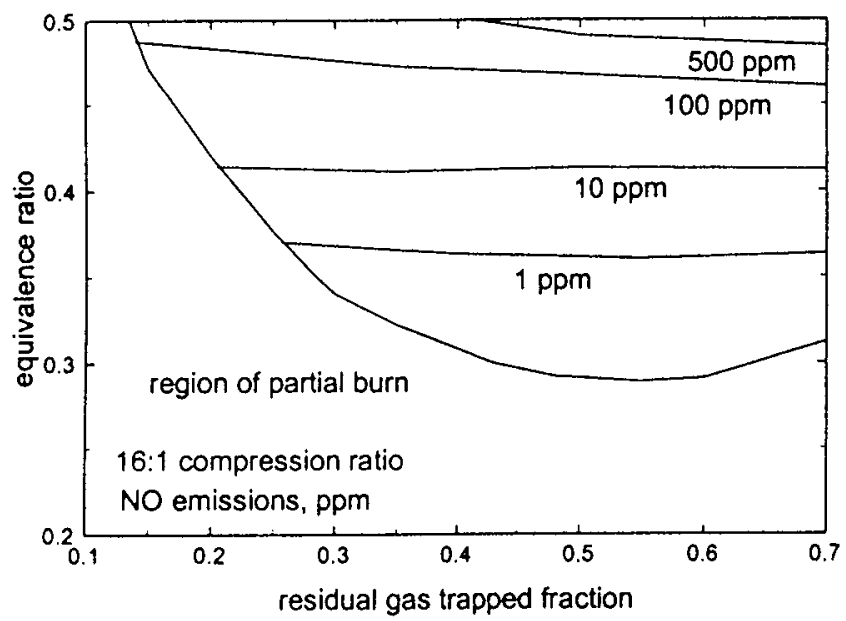

Figure 6. Contours of NO emissions in PPM for methane $\mathrm{HCCl}$ combustion at 16:1 CR, $1200 \mathrm{rpm}$ and 3 atmospheres of absolute intake pressure.

Figure 9 also shows lines of constant NO emissions (dotted lines). These lines may also represent a limit to engine operation, depending on the emissions standard that has to be met. As shown in the figure, NO emissions may represent an important limit at low compression ratios. For high compression ratios, the maximum high pressure is likely to be reached before NO emissions are significant.

\section{COMPARISON WITH EXPERIMENTAL RESULTS}

A recent paper (Christensen et al., 1998) has provided $\mathrm{HCCl}$ data for a four-stroke engine running on ethanol, octane, and natural gas. This section shows a comparison between the experimental results and HCT results for two of the experimental conditions. The comparison is for natural gas fuel. As in the cited work, the volume composition of the natural gas is: $91.1 \%$ methane, $4.7 \%$ ethane, $1.7 \%$ propane, $1.4 \%$ n-butane, $0.6 \%$ nitrogen, and $0.5 \%$ carbon dioxide Only two conditions are used in the comparison, but all the results follow the same general trends. The two conditions used in the comparison are:

Condition 1: Natural gas, 17:1 compression ratio, 3 bar intake pressure, 0.31 equivalence ratio, and $70^{\circ} \mathrm{C}$ intake temperature.

Condition 2: Natural gas, 19:1 compression ratio, 3 bar intake pressure, 0.26 equivalence ratio, and $50^{\circ} \mathrm{C}$ intake temperature.

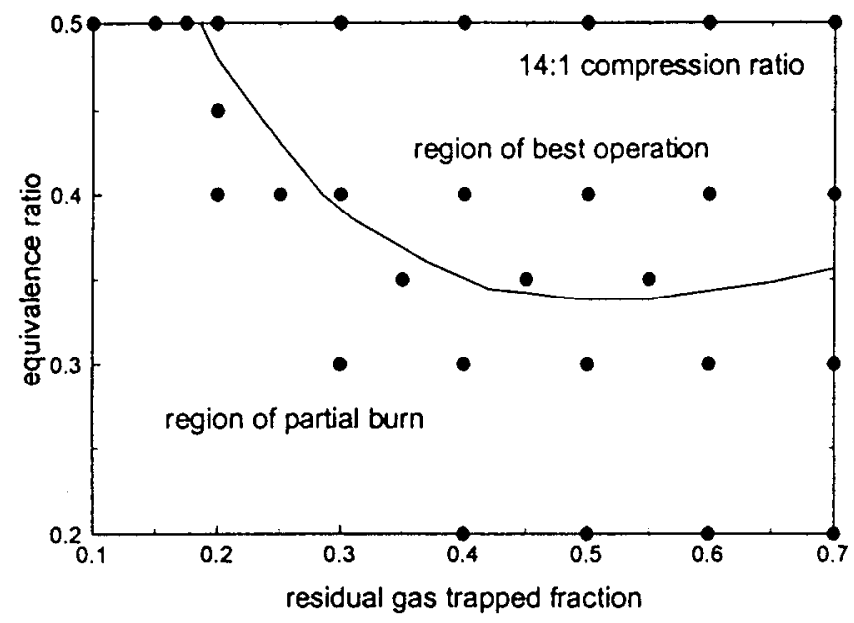

Figure 7. Map of the regions of acceptable operation in the $\mathrm{HCCl}$ mode for an engine with a 14:1 compression ratio at $1200 \mathrm{rpm}$ and 3 atmospheres of absolute pressure at the intake, running on methane. Points indicate simulations done with HCT code.

The comparison is complicated by the fact that the temperature at $\mathrm{BDC}$ before the compression stroke is not known. This temperature is higher than the intake temperature, due to heat transfer from the intake manifold, cylinder walls, and residual gases. Instead of attempting the difficult task of accurately calculating the temperature at $\mathrm{BDC}$, this temperature has been used as a free parameter to match the start of combustion. It was found that adding $40 \mathrm{~K}$ to the intake manifold temperature results in values for $\mathrm{BDC}$ temperature that match the start of combustion reported in the experiments. This adjustment appears appropriate, since $40 \mathrm{~K}$ is a reasonable value for the temperature increase due to heat transfer and residuals.

Once the start of combustion is matched, other combustion parameters can be compared. The results are shown in Figure 10. The figure shows the ratio of the simulation results to the experimental results, for four engine parameters: gross indicated efficiency, burn duration, maximum cylinder pressure, and gross IMEP, for the two operating conditions previously described (17:1 and 19:1 compression ratio). The numbers on top of the bars show the numerical and experimental results that are divided to obtain the ratio shown in the figure. For example, 59/48 on top of the first indicated 
efficiency bar indicates that the calculated indicated efficiency is $59 \%$, and the experimental value is $48 \%$.

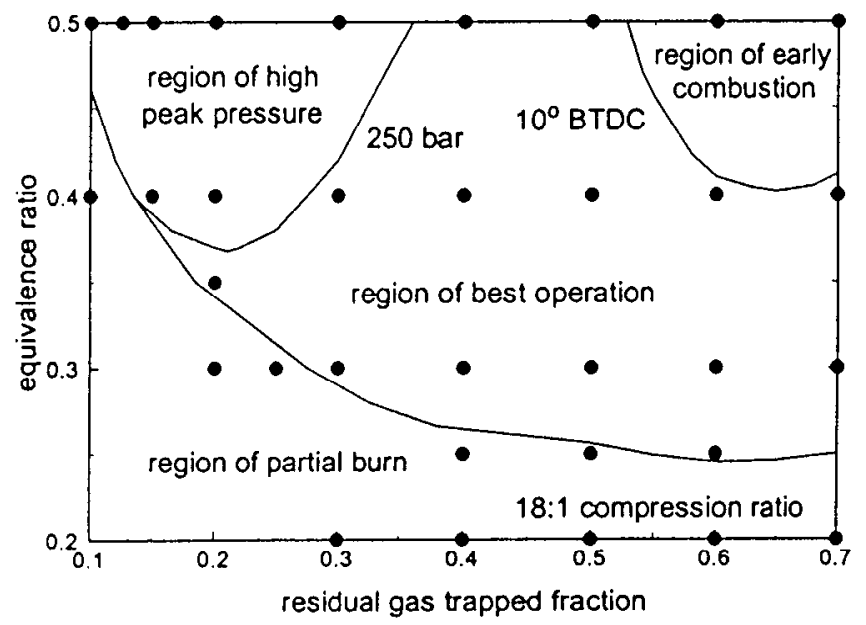

Figure 8. Map of the regions of acceptable operation in the $\mathrm{HCCl}$ mode for an engine with a 18:1 compression ratio at $1200 \mathrm{rpm}$ and $3 \mathrm{atmospheres}$ of absolute pressure at the intake, running on methane. Points indicate simulations done with HCT code.

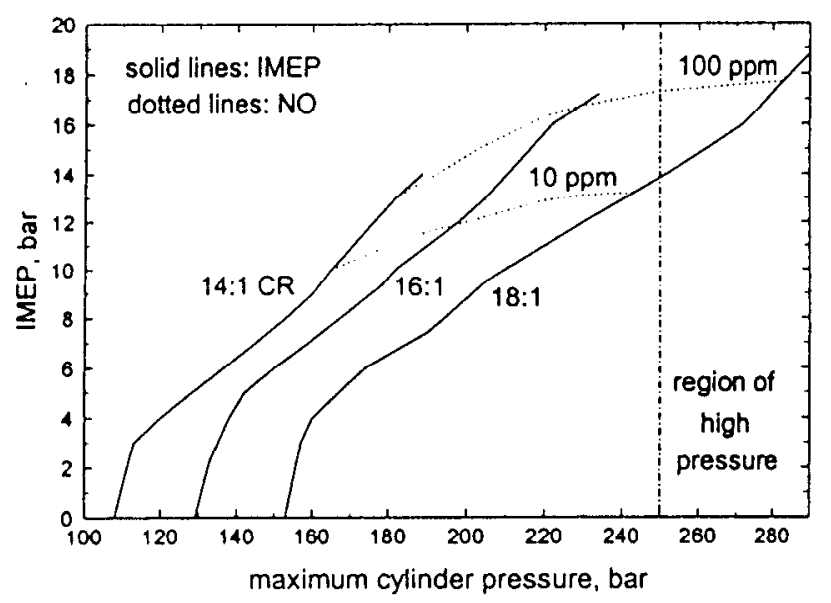

Figure 9. Gross IMEP as a function of maximum cylinder pressure, for the three compression ratios being analyzed. The figure shows the maximum allowable cylinder pressure (250 bar), and dotted lines that indicate points of constant NO emissions.

The results are consistent with what should be expected from a single-zone model. Calculated values for indicated efficiency and IMEP are 10 to $20 \%$ higher than the experimental values, mainly because the single-zone model predicts that the fuel bums to completion. Multiplying these results by the combustion efficiency (reported by Christensen et al., as being about $92 \%$ ), would result in a much better agreement between experimental and numerical results. The single-zone model also underpredicts the burn duration. As a consequence, maximum cylinder pressure is higher than the experimental result.

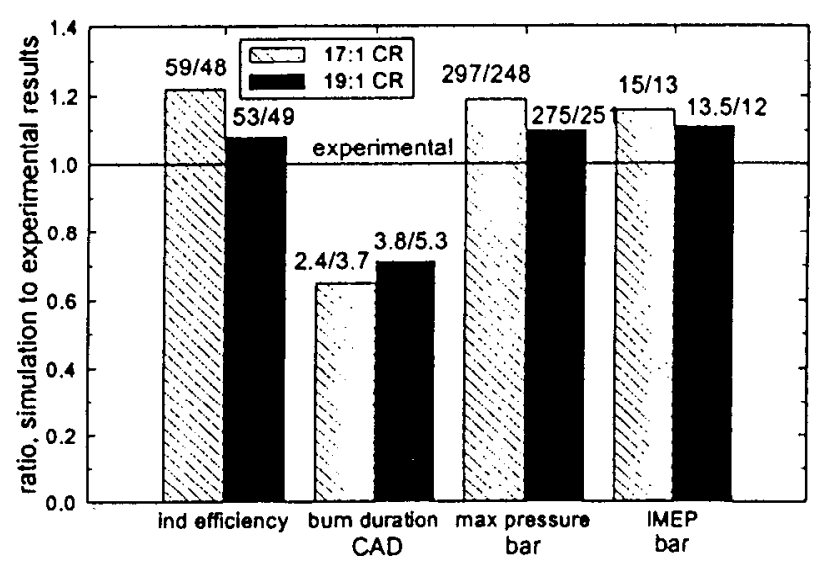

Figure 10. Ratio of HCT simulation results to experimental results (from Christensen et al., 1998), for natural gas fuel, for four engine parameters, for two operating points: 17:1 compression ratio, and 19:1 compression ratio. The numbers on top of the bars show the numerical and experimental results that are divided to obtain the ratio shown in the flgure.

\section{CONCLUSIONS}

* Based on these HCT simulations there appears to be a region of acceptable engine operation using methane to achieve the $\mathrm{HCCl}$ combustion process.

* High indicated efficiency at low power levels should be achievable.

* NO emission levels of less than 100 ppm can be achieved without a catalyst at equivalence ratios less than 0.5 .

* Equivalence ratio and residual gas trapping (RGT) are likely to be adequate controls if direct pressure feedback information is used to reduce cycle-to-cycle variation.

* Maximum cylinder pressure and NO emissions may impose upper bounds on engine IMEP. For engines with a maximum allowable cylinder pressure, an optimum compression ratio is likely to exist for which a maximum IMEP is obtained. This optimum compression ratio can be used for fuel characterization for $\mathrm{HCCl}$ applications.

* A comparison between simulation and experimental results has been done. The comparison shows that, as expected, the singlezone model overpredicts engine efficiency, maximum pressure and IMEP; and it underpredicts burn duration.

\section{ACKNOWLEDGMENTS}

Work performed under the auspices of the U.S. Department of Energy by Lawrence Livermore National Laboratory under Contract W-7405 ENG-48. 


\section{REFERENCES}

Amsden, A.A., 1993, "KIVA-3: A KIVA Program with Block-

Structured Mesh for Complex Geometries," Los Alamos National Laboratory Report LA-12503-MS.

Asai, M., Kurosaki, T., and Okada, K., 1995, "Analysis of Fuel Economy Improvement and Exhaust Emission Reduction in a TwoStroke Engine by Using an Exhaust Valve," SAE Paper 951764.

Automotive Engineering, 1997, "Honda Readies Activated Radical Combustion Two-Stroke Engine for Production Motorcycle," December, pp. 101-102.

Christensen, M., Johansson, B., Amneus, P., and Mauss, F., 1998, "Supercharged Homogeneous Charge Compression Ignition," SAE Paper 980787.

Curran, J. H., Gaffuri, P., Pitz, W. J., Westbrook, C. K., and Leppard, W. R., 1995, "Autoignition Chemistry of the Hexane Isomers: An Experimental and Kinetic Modeling Study," SAE paper 952406.

Frenklach, M.,Wang, H., Goldenberg, M., Smith G. P., Golden, D. M., Bowman, C. T., Hanson, R. K., Gardiner, W. C., and Lissianski, V., 1995, "GRI-Mech - An Optimized Detailed Chemical Reaction Mechanism for Methane Combustion", GRI Topical Report No. GRI-95/0058.

Gray, A.W., and Ryan, T.W., 1997, "Homogeneous Charge Compression Ignition (HCCI) of Diesel Fuel," SAE Paper 971676.

Green, R. M., Cernansky, N. P., Pitz, W. J., and Westbrook, C. K., 1987. "The Role of Low Temperature Chemistry in the Autoignition of n-Butane," SAE paper 872108.

Hashizume, T., Miyamoto, T., Akagawa, H., and Tsujimura, K., 1998, "Combustion and Emission Characteristics of Multiple Stage Diesel Combustion," SAE Paper 980505.

Heywood, J. B., 1988, Internal Combustion Engine Fundamentals, McGraw-Hill, Inc., New York, NY.

Iida, N., 1997, "Alternative Fuels and Homogeneous Charge Compression Ignition Combustion Technology," SAE Paper 972071.

Ishibashi, Y, and Asai, M., 1996, "Improving the Exhaust Emissions of Two-Stroke Engines by Applying the Activated Radical Concept," SAE Paper 960742.

Ishibashi, Y., and Asai, M., 1998, "A Low Pressure Pneumatic Direct Injection Two-Stroke Engine by Activated Radical Combustion Concept," SAE Paper 980757.
Jensen, S. P., 1994, "A Retrofit System to Convert a Locomotive to Natural Gas Operation," ASME, ICE-Vol 21, Natural Gas and Alternative Fuels for Engines, Book No. G00830.

Kong, S.C., Ayoub, N., and Reitz, R.D., 1992, "Modeling Combustion in Compression Ignition Homogeneous Charge Engines," SAE Paper 920512.

Lund, C. M., 1978 "HCT - A General Computer Program for Calculating Time-Dependent Phenomena Involving OneDimensional Hydrodynamics, Transport, and Detailed Chemical Kinetics," Lawrence Livermore National Laboratory report UCRL52504.

Najt, P. M. and Foster, D. E., 1983, "Compression-Ignited Homogeneous Charge Combustion," SAE paper 830264.

Nakagome, K., Shimazaki, N., Niimura, K., Kobayashi, S., 1997, "Combustion and Emission Characteristics of Premixed Lean Diesel Combustion Engine," SAE paper 970898.

Onishi, S., Jo, S. H., Shoda, K., Jo, P. D., and Kato, S., 1979, "Active Thermo-Atmosphere Combustion (ATAC) - A New Combustion Process for Internal Combustion Engines," SAE paper 790501 .

Pitz, W. J., Westbrook, C. K., and Leppard, W. R., 1991, "Autoignition Chemistry of C4 Olefins Under Motored Engine Conditions: A Comparison of Experimental and Modeling Results," SAE paper 912315 .

Ryan, T. W. III and Callahan, T. J., 1996 "Homogeneous Charge Compression Ignition of Diesel Fuel," SAE paper 961160.

Smith, J.R., Aceves, S.M., Westbrook, C. and Pitz, W., "Modeling of Homogeneous Charge Compression Ignition (HCCl) of Methane," Proceedings of the 1997 ASME Internal Combustion Engine Fall Technical Conference, Paper No. 97-ICE-68, ICE-Vol. 29-3, pp. 8590.

Theobald, M. A. and Henry, R., 1994, "Control of Engine Load Via Electromagnetic Valve Actuators," SAE paper 940816.

Thring, R. H., 1989, "Homogeneous Charge Compression Ignition (HCCI) Engines," SAE paper 892068.

Westbrook, C. K., Pitz, W. J., and Leppard, W. R., 1991, "The Autoignition Chemistry of Paraffinic Fuels and Pro-Knock and AntiKnock Additives: A Detailed Chemical Kinetic Study," SAE paper 912314. 
Westbrook, C. K., Warnatz, J., and Pitz, W. J., 1988, "A Detailed Chemical Kinetic Reaction Mechanism for the Oxidation of isoOctane and $n$-Heptane over an Extended Temperature Range and its Application to Analysis of Engine Knock," Twenty-Second Symposium (International) on Combustion, p. 893, The Combustion Institute, Pittsburgh.

Woschni, G., 1967, "Universally Applicable Equation for the Instantaneous Heat Transfer Coefficient in the Internal Combustion Engine," SAE Paper 670931. 